\title{
Laparoscopic adrenalectomy for metachronous ipsilateral metastasis following nephrectomy for renal cell carcinoma
}

\author{
Petr Stránský1, Viktor Eret' ${ }^{1,2}$, Tomáš Ürge ${ }^{1,2}$, Ivan Trávníček ${ }^{1,2}$, Zdeněk Chudáček ${ }^{3}$, Ondřej Hes ${ }^{2,4}$, Milan Hora ${ }^{1,2}$ \\ ${ }^{1}$ Department of Urology, Faculty Hospital, Pilsen, Czech Republic \\ 2Faculty of Medicine, Charles University in Prague, Pilsen, Czech Republic \\ ${ }^{3}$ Department of Radiology, Faculty Hospital, Pilsen, Czech Republic \\ ${ }^{4}$ Department of Pathology, Faculty Hospital, Pilsen, Czech Republic
}

Videosurgery Miniinv 2013; 8 (3): 221-225

DOI: $10.5114 /$ wiitm.2011.33813

\begin{abstract}
Introduction: Although laparoscopic adrenalectomy $(L A)$ is considered as a gold standard approach for adrenalecto$m y$, there are minimal data describing options and outcomes of LA after previous ipsilateral nephrectomy (PIN).

Aim: To describe our results in a group of patients who underwent LA after PIN.

Material and methods: From August 2004 to October 2012 we performed at our institution 88 LA. Of this amount we performed 5 LA for metachronous metastasis of renal cell carcinoma (RCC) after PIN. This group was compared to a group without previous nephrectomy.

Results: The group comprised 4 men (80\%) and 1 woman (20\%); the mean age at the time of surgery was $66.8 \pm 8.5$ (range: 60-77) years; the mean period between nephrectomy and adrenalectomy was 5.2 (range: 1.5-14) years; the operating time was longer in patients after PIN for $7 \mathrm{~min}$; the mean blood loss was higher by $22 \mathrm{ml}$; duration of hospitalization was shorter by 1.3 days, paradoxically, compared with patients without PIN. There was no need for conversion to open surgery and we did not observe any other complications.

Conclusions: Laparoscopic adrenalectomy for metastasis of RCC after PIN is a technically feasible method in selected patients and it is associated with no significant differences in perioperative data in comparison with the group without prior nephrectomy. The patients benefit from minimally invasive surgery. The performance has required an experienced laparoscopic surgeon.
\end{abstract}

Key words: laparoscopy, adrenalectomy, kidney cancer, tumour metastases.

\section{Introduction}

Surgical removal of metastases from renal cell carcinoma if it is technically possible is believed to be the best therapeutic possibility. This opinion is widely accepted although it has come only from retrospective studies. The results of individual authors' data have significantly varied and depended on the particular constitution of an evaluated complex [1, 2].
In spite of the development of a targeted molecular therapy, the surgical therapy may be recommended to patients with metachronous adrenal metastases either with or in the absence of systemic therapy [1-3].

Laparoscopic adrenalectomy is considered as a gold standard of care for patients with small adrenal masses [4]. In patients who underwent previous ipsilateral partial or radical nephrectomy, laparo- 
scopic approaches may not be considered because of obliteration of retroperitoneal landmarks, intraperitoneal adhesions and scarring at the potential operative site.

\section{Aim}

The purpose of this article is to review our experience with laparoscopic adrenalectomy for metastatic RCC (mRCC) after previous ipsilateral nephrectomy (PIN).

\section{Material and methods}

In the period from August 2004 to October 2012 we performed at our institution 88 laparoscopic adrenalectomy (LA). Five LA were performed for metachronous metastasis of renal cell carcinoma after PIN. In the same period only one open adrenalectomy was performed for extensive metastasis of renal cell carcinoma located behind the inferior vena cava and therefore it was unsuitable for laparoscopic operation (Photo 1).

\section{Surgical technique}

The technique of LA is well described and may be performed using a transperitoneal or retroperitoneal approach [4]. However, the retroperitoneum is obliterated in patients who have undergone nephrectomy. Therefore, a lateral transperitoneal approach is used for all the patients with PIN.

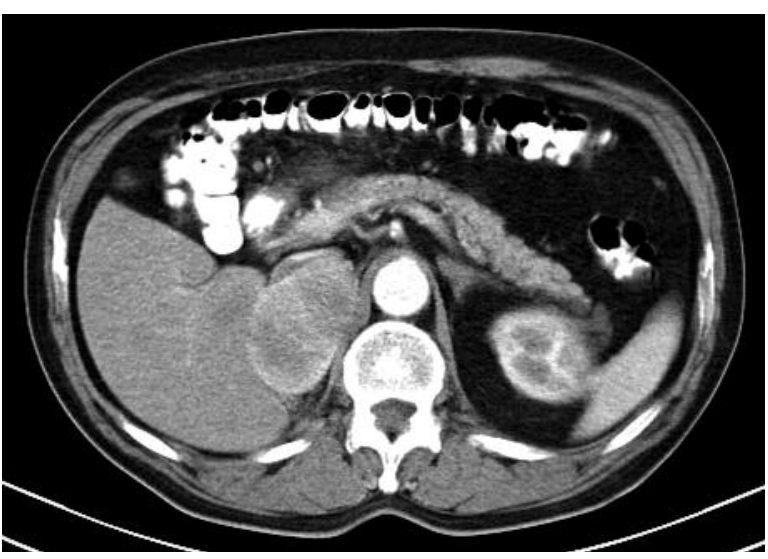

Photo 1. Extensive renal cell carcinoma metastasis into the right adrenal gland, the state after transperitoneal radical nephrectomy on the right in another department 5 years ago. The patient was indicated for open adrenalectomy
After insertion of a urinary catheter, a patient is turned to the lateral flank position with elevation of the operated side. It causes medial dislocation of the bowel by gravity and avoidance of intraperitoneal adhesions. We create capnoperitoneum using a Veress needle up to pressure $12 \mathrm{~mm} \mathrm{Hg}$. We insert first a $10 \mathrm{~mm}$ videoport laterally from the musculus rectus abdominis for $30^{\circ}$ optics. Subsequently we continue with revision of the abdominal cavity, and insert another $11 \mathrm{~mm}$ port laterally from the videoport, so that we can disrupt intraperitoneal adhesions. During preparation we use a common hook with coagulation or cutting, a harmonic scalpel or the bipolar vessel sealing system LigaSure ${ }^{\circledR}$, Blunt tip $35 \mathrm{~mm}$ instrument. After dissection of adhesions we classically insert two other $5 \mathrm{~mm}$ ports under optical control below the ribs. In right-sided cases we use a $5 \mathrm{~mm}$ port under the processus xiphoideus or a $3 \mathrm{~mm}$ port below the ribs for liver retraction.

A crucial aspect of dissection in patients undergoing LA in the setting of PIN is the liberal use of sharp dissection with endoshears. Blunt dissection can lead to injury of normal organs, dissection into incorrect tissue planes and potentially tumour violation. The liver elevation and mobilization of hepatic flexure is necessary on the right side, the mobilization of the splenic flexure and spleen on the left side. Perfect orientation in the whole operated field and identification of significant structures are highly important; it means the identification of the adrenal gland with the tumour, renal artery and vein stumps bilaterally, duodenum, vena cava inferior on the right side, tail of pancreas, splenic artery and aorta on the left side. Laparoscopic ultrasonography can help with identification of critical structures. The adrenal vein is controlled by using $5 \mathrm{~mm}$ polymer lockable clips Hem-oLok $^{\circledR}$ Weck (size ML).

After complete adrenal release, we insert the specimen into the plastic bag that is extracted by widening one of the ports. The scar after previous nephrectomy could be used for extraction of the specimen too. We use incision of a lateral port for abdominal cavity drainage (Photos 2-4).

\section{Results}

From August 2004 to October 2012 we performed 88 LA at our institution. Of this amount 5 LA were performed for metachronous metastasis of renal cell carcinoma after PIN. 


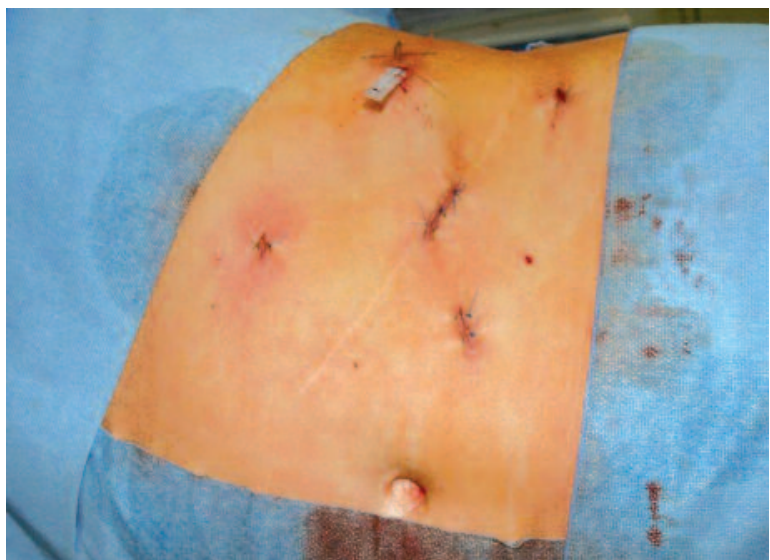

Photo 2. View of the abdominal wall following laparoscopic adrenalectomy on the left. The scar after previous transperitoneal nephrectomy used for extraction of the specimen

The group comprised 4 men (80\%) and 1 woman (20\%). The mean age at the time of surgery was 66.8 \pm 8.5 (range: $60-77$ years).

The mean time from nephrectomy to adrenalectomy was 5.2 (range: 1.5-14) years. Patients' characteristics and results for each group are shown in Table I.

The mean blood loss was higher after PIN by $22 \mathrm{ml}$. The mean operating time was longer by $7 \mathrm{~min}$ compared with the group without previous nephrectomy. The patients after PIN were paradoxically hospitalized for a shorter period than patients without previous nephrectomy. This phenomenon was probably caused by the facts that we had no complications in this group, which would lengthen hospitalization, and the group was relatively small as well. There was no conversion in our group of patients after PIN. Results of patients undergoing LA after PIN are shown in Table II.

Three patients in the PIN group achieved complete remission and have no evidence of disease, 2 patients are alive with disease and with additional targeted therapy - sunitinib (Sutent ${ }^{\circledR}$ ).

At the same time we also performed 7 LA for metachronous metastasis of renal cell carcinoma in the contralateral adrenal gland.

\section{Discussion}

In the classical description of a radical nephrectomy for RCC, Robson and colleagues suggested that adrenalectomy should be performed as an integral

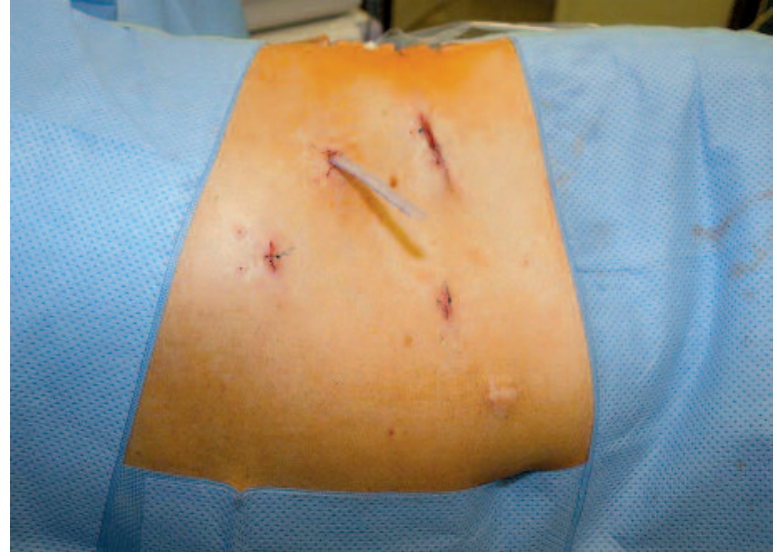

Photo 3. View of the abdominal wall following laparoscopic adrenalectomy on the left. The scar after previous laparoscopic nephrectomy used for extraction of the specimen

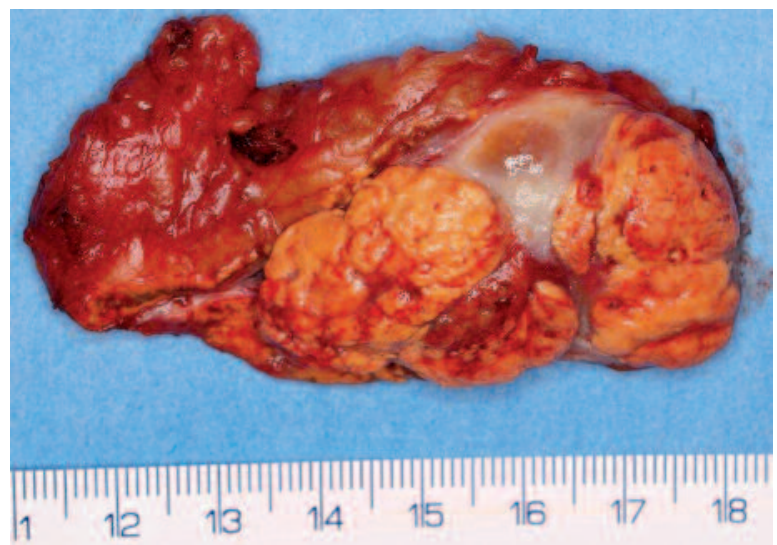

Photo 4. Adrenal gland with metastasis of clear cell renal cell carcinoma. On the left side of the specimen, the rest of the normal adrenal gland is visible

Table I. Patients' characteristics and results

\begin{tabular}{|lcc|}
\hline Parameter & $\begin{array}{c}\text { No previous } \\
\text { nephrectomy } \\
(n=83)\end{array}$ & $\begin{array}{c}\text { Previous } \\
\text { nephrectomy } \\
(n=5)\end{array}$ \\
\hline Age [years] & 58.9 & 66.8 \\
\hline Male & 32 & 4 \\
\hline Female & 51 & 1 \\
\hline Tumour size [cm] & 4.2 & 3.6 \\
\hline Estimated blood loss [ml] & 44 & 66 \\
\hline Surgery time [min] & 80 & 87 \\
\hline Length of hospitalization [days] & 5.9 & 4.6 \\
\hline
\end{tabular}


Table II. Results of patients undergoing laparoscopic adrenalectomy after previous ipsilateral nephrectomy

\begin{tabular}{|lcccccc|}
\hline Sex & Age [years] & $\begin{array}{c}\text { Previous } \\
\text { nephrectomy } \\
\text { approach }\end{array}$ & $\begin{array}{c}\text { TNM } \\
\text { classification } \\
\text { and grade }\end{array}$ & $\begin{array}{c}\text { Time from } \\
\text { nephrectomy } \\
\text { to LA [months] }\end{array}$ & $\begin{array}{c}\text { Time from } \\
\text { LA to last } \\
\text { follow-up [months] }\end{array}$ & $\begin{array}{c}\text { Condition } \\
\text { at last } \\
\text { follow-up }\end{array}$ \\
\hline F & 60.4 & Open, transperitoneal & pT1bNOMO G I & 48 & 51 & Alive, sunitinib \\
\hline M & 61.3 & Open, transperitoneal & pT1bNOMO GI & 168 & 26 & NED \\
\hline$M$ & 74.7 & Open, transperitoneal & pT1aNOMO GII & 56 & 24 & Alive, sunitinib \\
\hline$M$ & 77.5 & Laparoscopic & pT1bNOMO GII & 24 & 11 & NED \\
\hline$M$ & 60.3 & Laparoscopic & pT1bNOM1 GI & 19 & 1 & NED \\
\hline
\end{tabular}

LA - laparoscopic adrenalectomy, NED - no evidence of disease

part of the surgery [5]. Modern series, however, have not shown a benefit to routinely removing the adrenal gland with radical nephrectomy. The adrenal gland may become involved by local extension, or lymphatic or haematogenous metastasis, with a $1 \%$ to $5 \%$ incidence of synchronous metastasis [6].

Ipsilateral adrenalectomy is indicated in patients with radiographic suspicion of adrenal involvement or when there is a large upper pole tumour and direct invasion of the adrenal gland is likely or when a normal adrenal gland cannot be excluded $[6,7]$.

Despite increased survival and improved response rates that are associated with the use of targeted therapies for $\mathrm{mRCC}$, the median overall survival continues to be less than 2 years, with complete remission being seen rarely [8]. After nephrectomy, however, the time course of metastatic disease progression is variable with some patients progressing quickly while other patients slowly progress or stabilize with low volume metastasis. Patients with $\mathrm{mRCC}$ who are otherwise healthy and have oligometastatic disease often undergo metastasectomy because they can achieve surgical complete remission and a prolonged disease-free interval. Although several series have noted the association of surgical resection of metastases with improved survival, it is difficult to prove the survival benefit of surgery, given that these patients are highly selected. In addition, even with known prognostic factors, it is not clear which patients will benefit from metastasectomy. Published results show $51 \%$ to $88 \%$ survival in patients with intermediate and high-risk disease undergoing metastasectomy through 24 months median follow-up [9].

Adrenal metastases after ipsi- or contralateral nephrectomy are not rare [10] and adrenalectomy indicated for removal of metastases has been associated with prolonged survival [11]. In patients with adrenal metastases after nephrectomy, open adrenalectomy necessitates a large incision to gain access for removal of a small gland. In addition to the possible benefits of less pain and a quicker recovery, patients may be able to return to systemic therapy for mRCC faster when applied laparoscopic techniques are compared with open surgery. Recovery time is an important fact, because agents are frequently withheld after surgery because of concerns with wound healing while receiving therapies that target angiogenic pathways [12, 13].

Also in LA a single-port approach similar to nephrectomy can be used [14]. We have used this approach totally in 9 LA. Due to the technical difficulties, we did not use a single-port approach for LA after PIN.

\section{Conclusions}

Laparoscopic adrenalectomy for metastasis of RCC after PIN is a technically feasible method in selected patients and is associated with no significant differences in perioperative data in comparison with the group without prior nephrectomy. The laparoscopic procedure is always performed transperitoneally; considering PIN at first it is necessary to disrupt intraperitoneal adhesions. During the operation perfect orientation in already operated terrain and the identification of significant structures are very important. The surgeon who performs this procedure should be experienced in standard LA as well as reoperative open and laparoscopic surgery. The patient benefits from minimally invasive surgery and considering faster recovery it is possible to timely deploy systematic therapy for $\mathrm{MRCC}$ as necessary. 


\section{Acknowledgments}

Supported by the project of the Ministry of Health of the Czech Republic for conceptual development of research organization 00669806 - University Hospital in Pilsen, Czech Republic and by the Charles University Research Fund (project number P36).

\section{References}

1. Kavolius JP, Mastorakos DP, Pavlovich C, et al. Resection of metastatic renal cell carcinoma. J Clin Oncol 1998; 16: 2261-6.

2. Leibovich BC, Cheville JC, Lohse ChM, et al. A scoring algorithm to predict survival for patients with metastatic clear cell renal carcinoma: a stratification tool for prospective clinical trials. J Urol 2005; 174: 1759-63.

3. Hora M, Stransky P, Eret V, et al. Integration of surgery and molecular targeted therapy in advanced renal cell carcinoma. Ces Urol 2011; 15: 149-57.

4. Stransky P, Hora M, Eret V, et al. Laparoscopic adrenalectomy. Rozhl Chir 2009; 88: 514-20.

5. Robson CJ, Churchill BM, Anderson W. The results of radical nephrectomy for renal cell carcinoma. J Urol 1969; 101: 297-301.

6. Ljungberg B, Cowan NC, Hanbury DC, et al. EAU Guidelines on renal cell carcinoma: the 2010 update. Eur Urol 2010; 58: 398-403.

7. Stransky P, Hora M, Eret V, Ürge T. Surgical options and indications for advanced and metastatic kidney disease. Postgrad Med 2010; 12: 355-60.

8. Heng DY, Xie W, Regan MM, et al. Prognostic factors for overall survival in patients with metastatic renal cell carcinoma treated with vascular endothelial growth factor - targeted agents: results from a large, multicenter study. J Clin Oncol 2009; 27: 5794-9.

9. Eggener SE, Yossepowitch O, Pettus JA, et al. Renal cell carcinoma recurrence after nephrectomy for localized disease: predicting survival from time of recurrence. J Clin Oncol 2006; 24 3101-6.

10. Saitoh H, Nakayama M, Nakamura K, Satoh T. Distant metastasis of renal adenocarcinoma in nephrectomized cases. J Uro 1982; 127: 1092-5.

11. Antonelli A, Cozzoli A, Simeone C, et al. Surgical treatment of adrenal metastasis from renal cell carcinoma: a single centre experience of 45 patients. BJU Int 2006; 97: 505-8.

12. Margulis V, Matin SF, Tannir N, et al. Surgical morbidity associated with administration of targeted molecular therapies before cytoreductive nephrectomy or resection of locally recurrent renal cell carcinoma. J Urol 2008; 180: 94-8.

13. Abel EJ, Karam JA, Carrasco A, Matin SF. Laparoscopic adrenalectomy for metachronous metastases after ipsilateral nephrectomy for renal-cell carcinoma. J Endourol 2011; 25: 1323-7.

14. Chłosta P, Drewa T, Obarzanowski M, et al. Do we need a cosmetic effect for radical nephrectomy? Laparoendoscopic singlesite surgery would help to answer this question. Videosurgery Miniinv 2011; 6: 1-4.

Received: 16.12.2012, accepted: 2.2.2013. 